\title{
Chronic Hypoxemic Syndrome and Congenital Heart Disease in Adults: A Multisystemic Disorder
}

\author{
John Araujo* \\ Department of Clinic and Research Cardiology, Soma \& Meintegral Clinic, Colombia
}

Submission: February 13, 2018; Published: May 14, 2018

*Corresponding author: John Araujo, Cardiologist-Echocardiologist in Pediatric and Adult Congenital Heart Diseases, Fellowship Integrated Unit of Congenital Heart Diseases of Adolescent and Adult Vall d'Hebron-Sant Pau, Vall d'Hebron University Hospital, Barcelona, Catalonia, Spain, Department of Clinic and Research Cardiology, Soma \& Meintegral Clinic, Colombia, Tel: +5745768651; Email: johnjairoaraujo@gmail.com

\begin{abstract}
Congenital heart disease is the most frequent malformation, many cases are complex cyanotic congenital heart defects characterized by low arterial oxygen saturation. Unrepaired intracardiac or extracardiac congenital heart defects which causes a persistent right to left shunt, they are responsible for hypoxemic syndrome, this is a multisystemic disorder affecting various organs and symstems: hematopoietic, central nervous, gastrointestinal, urinary, cardiovascular, Immune, musculoskeletal and endocrine. The objective this review is to explain the pathophysiological mechanisms adapted to the chronic hypoxia, the consequences derived from the affectation in the different systems. The diagnostic approach and management in centers specialized in adults with congenital heart disease. This review was made with articles search sources in databases PubMed, ScienceDirect, OVID, HINARI, SciELO, MD Consult. At the end of the article review recommendations on lifestyle, exercise, travel, noncardiac surgery, contraception and pregnancy, are given.
\end{abstract}

Keywords: Chronic hypoxemic syndrome; Congenital heart disease; Eisenmeger syndrome

\section{Introduction}

Congenital heart disease (CHD) in the United States (US) has an incidence of eight cases per 1,000 live births (LBs), and approximately one out of every 1,000 is complex [1]. In Europe, the EUROCAT (European Surveillance of Congenial Anomalies) and ECEMC (Spanish Collaborative Study of Congenital Malformations) reported an incidence of 4.7 and 1.6 per 1,000 LBs, respectively. In Latin America, the RYVEMCE (Registry and Epidemiological Surveillance of External Congenital Malformations) in Mexico, and the ECLAMC (Latin American Collaborative Study of Congenital Malformations), which covers most of South America, reported an incidence of one per 1,000 and 2.3 per 1,000 LBs, respectively [2]. Approximately $60 \%$ of CHD is diagnosed and treated early (before one year of age), and $30 \%$ during childhood and adolescence, prior to 16 years of age. An estimated $10 \%$ is diagnosed in adulthood [3].

Due to advances in pediatric cardiovascular surgery, currently more than $85 \%$ of children with CHD survive to adulthood [4]. In Europe, there is an estimated population of 2.3 million adults with CHD (ACHD), which surpasses the pediatric population of 1.9 million [5]. The ACHD population will continue to increase, with a 5-6\% annual growth rate [6]. In the US, in 2010, 1.4 million
ACHD were recorded, versus one million children with CHD. Of the ACHD, almost 350,000 have complex defects [7]. ACHD may be in two categories [8]:
A. ACHD who have survived naturally
B. ACHD who received some type of therapeutic intervention (surgery or percutaneous procedure) during childhood

Adults with CHD who have survived naturally are sub classified in three groups:

a. ACHD who have required a primary therapeutic intervention during adulthood.

b. ACHD who have not required a therapeutic intervention, but need ongoing clinical supervision and follow-up.

c. ACHD who are currently inoperable, whose only intervention option is a transplant, or in whom the surgical risk is greater than the risk of natural progression.

There are congenital heart diseases with a persistent right to left flow, or shunt, cause chronic hypoxemia known as hypoxemic syndrome (HS). It commonly manifests as cyanosis. 


\section{Terminology}

\section{Cyanosis}

A bluish tinge to the skin and mucous membranes which appears when the reduced capillary hemoglobin is $>5 \mathrm{~g} / \mathrm{dl}$. Its appearance depends on the amount of hemoglobin present. An anemic patient must have a greater percentage of desaturation in order to achieve $5 \mathrm{~g} / \mathrm{dl}$ of reduced hemoglobin and show cyanosis, while cyanosis will be more intense with increased hemoglobin levels [9]. Cyanosis may be:

a. Peripheral: Caused by increased oxygen extraction in the tissues.

b. Central: Caused by decreased oxygen saturation in arterial blood.

c. Hypoxemia: Is a central cyanosis (decreased oxygen saturation in arterial blood), caused by various disorders:

i. Cardiovascular: CHD with a right to left shunt, causing mixing of venous or unsaturated blood with arterial blood.

ii. Pulmonary: Altered alveolar-capillary diffusion, altered ventilation-perfusion ratio, alveolar hypoventilation.

iii. Neurological: Central alveolar hypoventilation.

iv. Environmental: Hypobaric or altitude hypoxia. v. Hemoglobin disorders: Methemoglobinemia, sulfhemoglobinemia, and carboxyhemoglobinemia

\section{Cyanotic Congenital Heart Disease (CCHD)}

An unrepaired congenital heart defect which causes a persistent right to left shunt, mixing venous and arterial blood. This mixing may occur in the atria (atrial septal defects), the ventricles (ventricular septal defects), or in the vasculature (arteriovenous fistulas, persistent ductus arteriosus). It produces a basal arterial oxygen saturation $<85 \%$ on room air (Figure 1). Various simple or complex CHDs not repaired during childhood, or diagnosed late in adulthood, cause hypoxemia. Some are:
A. Atrial septal defects
B. Ebstein's anomaly
C. Tetralogy of Fallot
D. Anomalous pulmonary or systemic venous return
E. Single ventricle
F. Pulmonary atresia
G. Transposition of the great arteries
H. Tricuspid atresia
I. Common arterial trunk
J. Eisenmenger syndrome

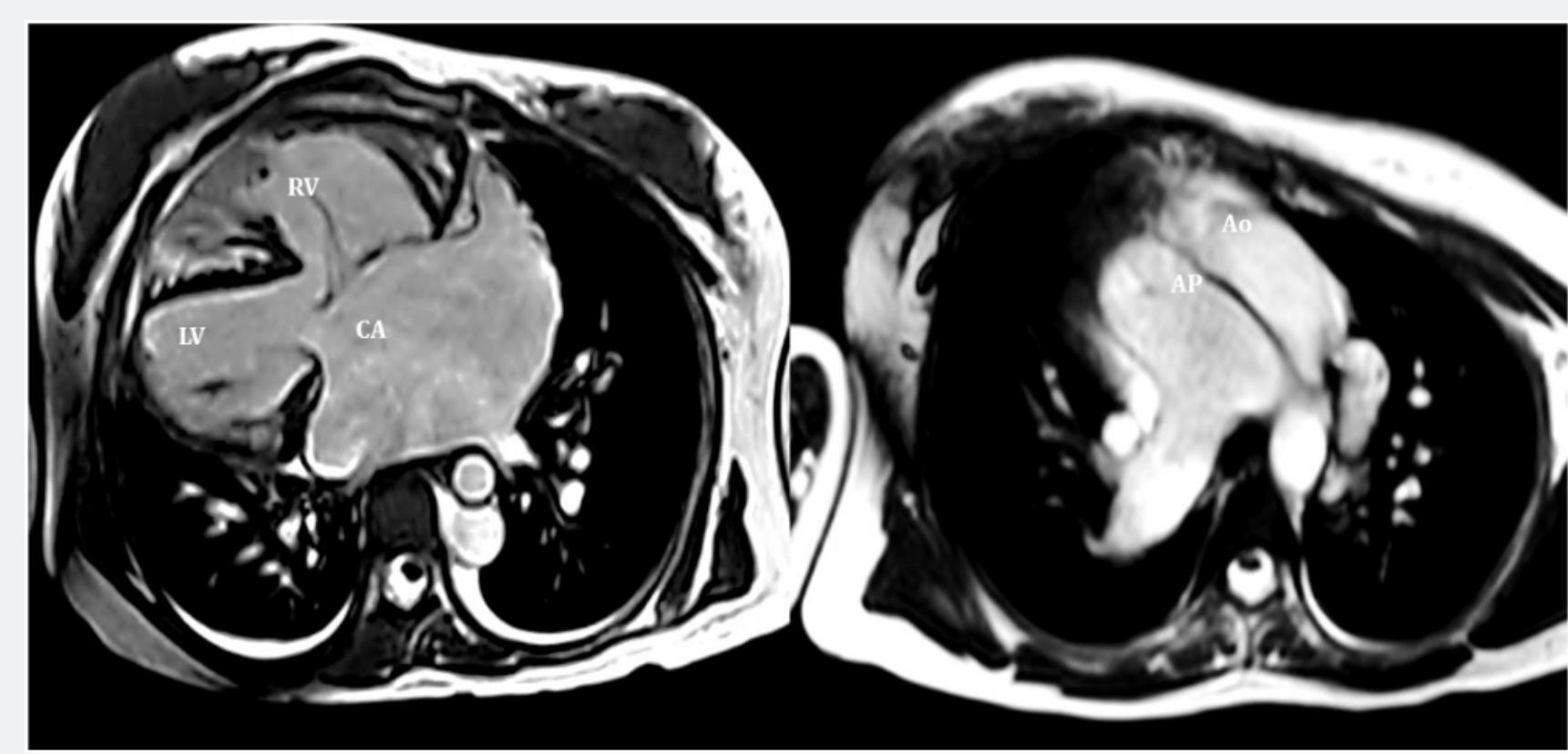

Figure 1: Cardiac resonance.

A: Female 26 year old, dextrocadia, levoisomerism, unrepared complet atrioventricular septal defect type C rastelli and eisenmeger syndrome.

B: The same case shows double right ventricle outflow. Ao: aorta, AP: pulmonary artery, dilated by pulmonary hypertension. RV: Right Ventricle; LV: Left Ventricle; AC: Common Atrium

\section{Clinical manifestations}

Hypoxemic syndrome is a multisystemic disorder affecting various organs. It causes serious chronic metabolic disorders which alter the normal homeostatic equilibrium. Consequently, the affected organs and systems function with a barely balanced physiology in which any noxa causes serious hemodynamic decompensation (Table 1). 


\section{Journal of Cardiology \& Cardiovascular Therapy}

Table 1: Multisystemic disorder in adults with congenital heart disease and chronic hypoxemic syndrome.

\begin{tabular}{|c|c|}
\hline System and Organ & Consequence \\
\hline Hematopoietic System & $\begin{array}{l}\text { Secondary erythrocytosis, iron deficiency, hyperviscosity syndrome, minor bleeds: bleeding gums, gastrointestinal } \\
\text { bleeds, epistaxis or metrorrhagia), severity bleeds: massive hemoptysis, digestive or cerebral bleeding, pulmonary } \\
\text { arterial thrombosis, thrombocytopenia, deficiency of vitamin K dependent clotting factors: factors II, VII, IX, X and factor } \\
\text { V. There is increased fibrinolytic activity and a deficit of the von willebrand factor }\end{array}$ \\
\hline Central Nervous System & $\begin{array}{l}\text { Neurological disorders due hyperviscosity syndrome: intense headaches, dizziness, syncope or pre-syncope, feeling } \\
\text { of being far away, tinnitus, diplopía, vague visions, amaurosis fugax, paresthesias on lips and fingers, mental fatigue, } \\
\text { stroke, brain abscess }\end{array}$ \\
\hline Gastrointestinal System & Gall stones, hyperbilirubinemia \\
\hline Urinary System & Hyperuricemia, gouty arthritis, kidney dysfunction, glomeurolopathy, proteinuria, hypocalcemia, electrolyte disorders \\
\hline Cardiovascular System & Arrhythmias, heart failure, coronary ischemia \\
\hline Immune System & Increased risk bacterial infections: brain abscess, endocarditis, pneumonia, dermatological disorders: hard-to-treat acne \\
\hline Musculoskeletal System & Myalgia, muscle weakness, effort intolerance, chest pain, hypertrophic osteoarthropathy \\
\hline Endocrine System & Neuroendocrine tumors: pheocromocytomas, paragangliomas, ganglioneuromas and neuroblastomas \\
\hline
\end{tabular}

\section{Hematopoietic system}

Secondary erythrocytosis (SE): One of the adaptive mechanisms to chronic hypoxemia, in the context of CCHD. It is defined as an increase in red blood cell mass, without an increase in all blood cell lines (polycythemia). There is a close inverse relationship between the severity of hypoxemia, iron depletion and the degree of erythrocytosis [10]. The goal of SE is to increase the supply of oxygen to the tissues, and it occurs in response to an increased production of erythropoietin by the juxtaglomerular apparatus in the kidney. SE produces increased blood viscosity, which also depends on other factors such as red blood cell size, aggregation and dispersion, plasma viscosity, temperature, and shear stress, among others. Under normal conditions, erythrocytes have a biconcave morphology, making them more deformable and flexible, while the microspherocytes present in iron deficiency do not. This explains the microcirculation problems of various organs and sytems (kidneys, brain and lungs), producing consequences such as in situ thromboses, kidney failure and ictus [11].

Hyperviscosity syndrome (HVS): A group of clinical signs and symptoms caused by a hemodynamic disorder of slowed blood flow resulting from increased blood viscosity. The hematocrit level has proven to be the main determinant. Symptoms usually appear with hemoglobin (Hgb) levels above 20mg/dl, and hematocrits (Hct) $>65 \%$. However, this increase does not occur in iron deficiency and microcytosis cases. Objective assessment should always be carried out with prior iron level quantification.

There are two forms of HVS:

i. Compensated: The Hgb and Hct levels remain stable, even with low iron levels. Hyperviscosity symptoms are absent, or, if they are present, are mild to moderate, even with Hct $>70 \%$.

ii. Decompensated: The Hgb and Hct levels have not been stabilized; they remain high regardless of the presence or absence of iron deficiency. Symptoms are always severe.

\section{Indications for phlebotomy}

Prophylactic phlebotomy to maintain a safe and arbitrary Hct $<65 \%$, in order to avoid hyperviscosity symptoms and cerebral thrombotic events, is one of the principal mistaken concepts in these patients, and is never justified. It may worsen symptoms by reducing the minute volume, brain perfusion and pulmonary flow. It causes iron depletion and increases hyperviscosity symptoms. High Hct levels, in and of themselves, do not warrant repeated phlebotomies which do not provide any clinical benefit.

Table 2:Hyperviscosity severity grade, the daily routine activities involve self-care, nutrition, sleep, concentration, memory, work performance.

\begin{tabular}{|c|c|c|}
\hline Grade & Symptoms & \\
\hline 0 & Absen & Symptoms and Relationship with Hyperviscosisty \\
\hline 1 & $\begin{array}{c}\text { Present symptoms but without interfering with } \\
\text { normal activities }\end{array}$ & $\begin{array}{c}\text { Intense headaches, dizziness, syncope or pre-syncope, a sense of far away distance, } \\
\text { tinnitus, diplopía, blurred visión, amaurosis fugaxparesthesias in lips and fingers, } \\
\text { mental fatigue, easy muscular fatigue, faintness, light-headedness }\end{array}$ \\
\cline { 1 - 2 } 2 & $\begin{array}{c}\text { Present symptoms but interferes with some but } \\
\text { not most activities }\end{array}$ & \\
\cline { 1 - 2 } & $\begin{array}{c}\text { Present symptoms but interferes with most or } \\
\text { all activities }\end{array}$ & \\
\hline
\end{tabular}

There are only two clear indications for phlebotomy [12]:

A. Moderate or severe hyperviscosity symptoms (grade 2 or 3) (Table 2).

B. Prior to surgery, if the Hct is $>65 \%$, to improve hemostasis.
The goal of phlebotomy is the temporary relief of hyperviscosity symptoms, achieved by only removing the sufficient and exact amount of blood. Clinical improvement, evaluated by improved exercise performance, is obtained 24 hours after the procedure. Other situations resemble hyperviscosity symptoms: dehydration, hypovolemia, hypothyroidism, heat 


\section{Journal of Cardiology \& Cardiovascular Therapy}

stroke, depression or even brain abscesses. The use of alcohol or medications which produce systemic hypotension should be determined, since generally these patients are medicated for conditions other than their CHD. All these causes should be ruled out before proceeding with phlebotomy.

Phlebotomy should not exceed $400-500 \mathrm{ml}$, and should be accompanied by simultaneous isovolumetric replacement with nomal saline to avoid hypovolemia. The arterial pressure should be monitored every 15 minutes and for up to one hour after completing the procedure. If the symptoms persist, the procedure may be repeated 24-48 hours later. Repeating the procedure more than three to four times per year is not recommended. Plasma or albumin infusions are not necessary. Patients with complex unrepaired CHD with intracardiac shunting should have air-guard filters in all their intravenous tubes, in order to avoid systemic air emboli (Figure 2).

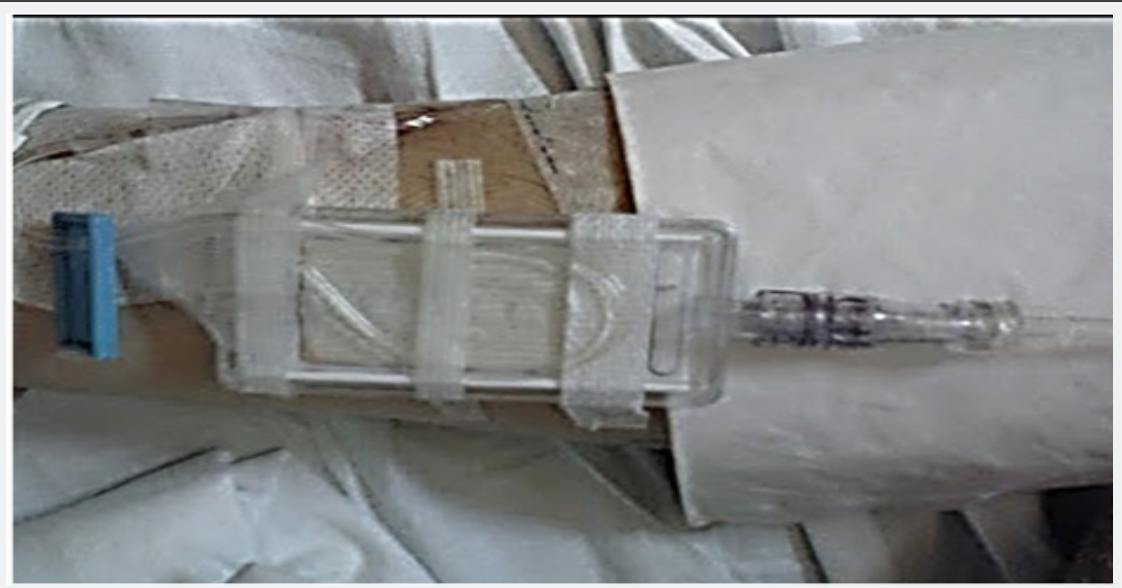

Figure 2: Air-guard filters in intravenous periferic lines

\section{HVS management algorithm (Figure 3)}

Anemia: Hgb levels of $15 \mathrm{gr} / \mathrm{dl}$ are normal in healthy adults, but are insufficient in patients with CCHD and Eisenmenger syndrome. Ranges of Hgb from 16-18gr/dl are safe, to achieve an SO2 of at least $85 \%$, which is acceptable for the baseline cardiopathy. Anemia is frequently not diagnosed on time. Losses due to minor bleeds (bleeding gums, gastrointestinal bleeds, epistaxis or metrorrhagia) are the most frequent cause. The depletion of iron stores and low production is the second cause. Repetitive phlebotomies are the third cause [13]. Monitoring of $\mathrm{Hgb}, \mathrm{Hct}$, erythrocyte indices, serum iron levels and transferrin saturation, vitamin B12, and folic acid is recommended every 6-12 months.

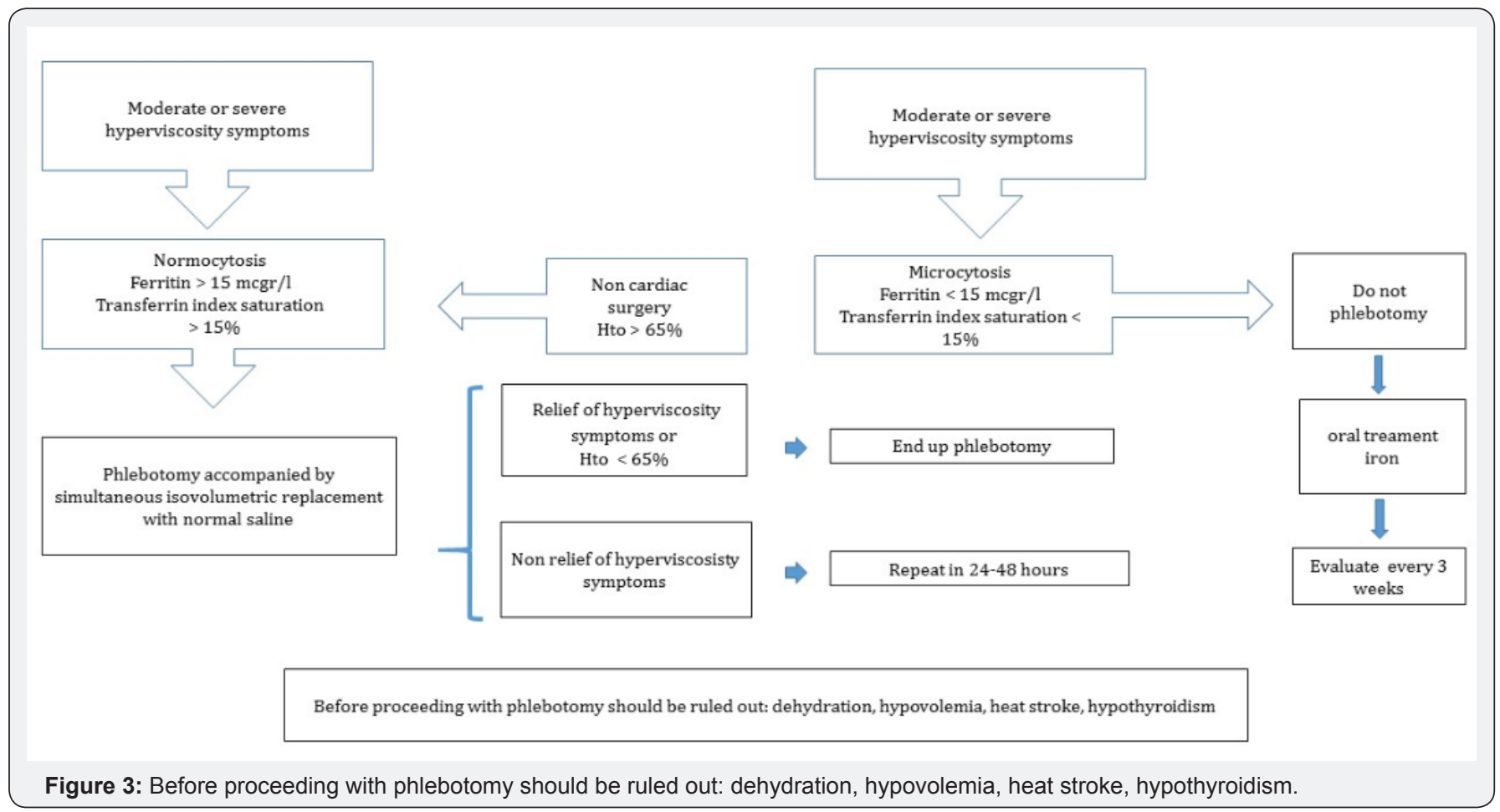


Management of Iron Deficiency: Ferritin $<15 \mathrm{mcgr} / \mathrm{lt}$, and transferrin saturation index $<15 \%$. Frequently associated with microcytosis, they confirm serum iron depletion. Oral treatment with $325 \mathrm{mg} /$ day of ferrous sulfate, or $65 \mathrm{mg} /$ day of elemental iron, is recommended. Parenteral administration is indicated if there is intolerance or a contraindication (peptic ulcer). Iron treatment should be administered with caution, evaluating iron stores and Hct and Hgb levels every three weeks, to avoid rebound phenomena.

Hemostatic alterations: thrombosis is frequent, occurring in the low-pressure chambers which are often dilated due to the progression of CHD. It is facilitated by rhythm alterations (atrial flutter and fibrillation) and prosthetic materials (valves, intra- or extra-cardiac tubes, electrodes) which increase the formation of thrombi. Intravascular devices (catheters, pacemakers, automatic implantable defibrillators [AID]) cause systemic emboli. Low levels of physical activity and sedentarism, associated with poor peripheral venous circulation, increase the incidence of thromboembolic events. Female sex, $<85 \%$ SO2, advanced age, ventricular dysfunction, dilation and calcification of the pulmonary arteries, and slowed blood flow have proven to be factors which increase the risk of thrombosis. Having an inborn error of coagulation does not prevent thrombotic events. Laminar thrombi in the pulmonary branches occur more frequently than imagined (a prevalence of 38\%) in the presence of dilation and calcification of the pulmonary arteries [14,15].

Hemorrhagic diatheses: Manifest as minor bleeds (bleeding gums, epistaxis, ecchymosis, metrorrhagia), or major bleeds such as hemoptysis. The presence of in situ laminar pulmonary thrombi and emboli has been documented as the cause of massive hemoptysis. Oral anticoagulation with warfarin has been controversial. Sandoval et al. reported no long-term survival advantages with the use of anticoagulants in patients with Eisenmenger syndrome and chronic cyanosis [16]. The severity of hemorrhagic events tends to be related to the amount of erythrocytes and the severity of hypoxemia. As mentioned previously, patients with significan erythrocytosis who are to undergo surgical interventions should receive phlebotomy at 24-48 hour intervals until a hematocrit no greater than $65 \%$ or a blood hemoglobin of $18-20 \mathrm{~g} / \mathrm{dl}$ is achieved, even if the patient has no symptoms suggestive of HVS.

General recommendations in hemoptysis: Discontinue medications that could affect coagulation, perform hemostatic analytical studies, and take a chest $\mathrm{x}$-ray. If there is alveolar infiltrate, a chest CT scan is recommended. The patient should be on bed rest with hydration measures, and codeine should be administered to avoid coughing spasms. In addition, antibiotics should be administered to avoid pulmonary superinfection. Hypovolemia and anemia should be corrected, if present. The possibility of administering platelets or fresh plasma should be evaluated (platelet replacement and fresh plasma transfusion are recommended with major bleeds and platelets $<100,000 / \mathrm{L}$ ).
When there is refractory hemoptysis, a pulmonary arteriography should be performed, locating and embolizing the bleeding vessel. Fibrobronchoscopy is not routinely indicated and may produce complications, especially in patients with pulmonary hypertension.

Thrombocytopenia: Platelet counts $<130,000 / \mathrm{ml}$ have been reported as a predictive factor of long-term mortality [17]. Under normal conditions, the megakaryocytes produced in the bone marrow must travel through the circulatory bed to the lung, where fragmentation occurs to form new platelets. In patients with CHD and ventricular or atrial septal defects, passage through the lungs is omitted. This causes an accumulation of megakaryocytes in the blood and a decreased number of circulating platelets, inversely proportional to the hematocrit and the magnitude of intracardiac shunting. The function of existing platelets is always altered, with reduced aggregation [18].

Deficiency of vitamin $K$ dependent clotting factors: Factors II, VII, IX, X and Factor V are deficient. There is increased fibrinolytic activity and a deficit of the von will ebrand factor. Clotting tests will always be altered. For a correct interpretation, the amount of citrate used should be adjusted to the hematocrit. Two formulas are used [19,20]:

A. The Toronto formula: One $\mathrm{ml}$ of anticoagulant $(3.8 \%$ citrate $)=1.6[(100$-hematocrit $) / 100]+0.02$ with a $10 \mathrm{ml}$ blood extraction.

B. Dr. Perloff's formula: (100-hematocrit/595-hematocrit)

As a recommendation, the administration of oral anticoagulants or antiplatelet agents is not warranted, since they aggravate the hemostasis problems and worsen hemorrhages [21]. The exceptions to this recommendation are situations with a clearly defined indication: sustained arrhythmias such as a trial flutter or a trial fibrillation, a history of thromboembolism or deep vein thrombosis, having prosthetics (catheters or intravascular electrodes), or pregnancy [22]. In these cases, strict control of anticoagulation levels must be carried out in centers with experience in managing ACHD, seeking to maintain a safe INR range between 2-2.5.

Blood glucose levels are always low due to consumption secondary to the elevated concentration of red cells. This must be taken into account before carrying out unnecessary glycemic corrections in patients.

\section{Central Nervous System}

\section{Thromboembolic events}

Cerebral ictus events have a multifactorial etiology (interaction between erythrocytosis, hypoxemia, altered microcirculation, endothelial dysfunction, arrhythmias, sedentarism, poor peripheral venous circulation). Symptoms of HVS may be confused with a thrombotic or embolic event. Assessment with high resolution brain imaging (computed axial tomography [CT] or brain magnetic resonance imaging [MRI]) is necessary, 
in addition to performing a detailed clinical evaluation. Adults with CHD having atrial or ventricular septal defects may produce paradoxical emboli.

\section{Brain abscess}

A clinical presentation of intense headache and mental deterioration should make the clinician suspect the diagnosis and be differentiated from HVS. On other occasions it manifests with neurological focal signs, convulsions, or neurologic deterioration. In all cases, a brain CT is indicated. Surgical drainage and antibiotic treatment should be performed (Figure 4).

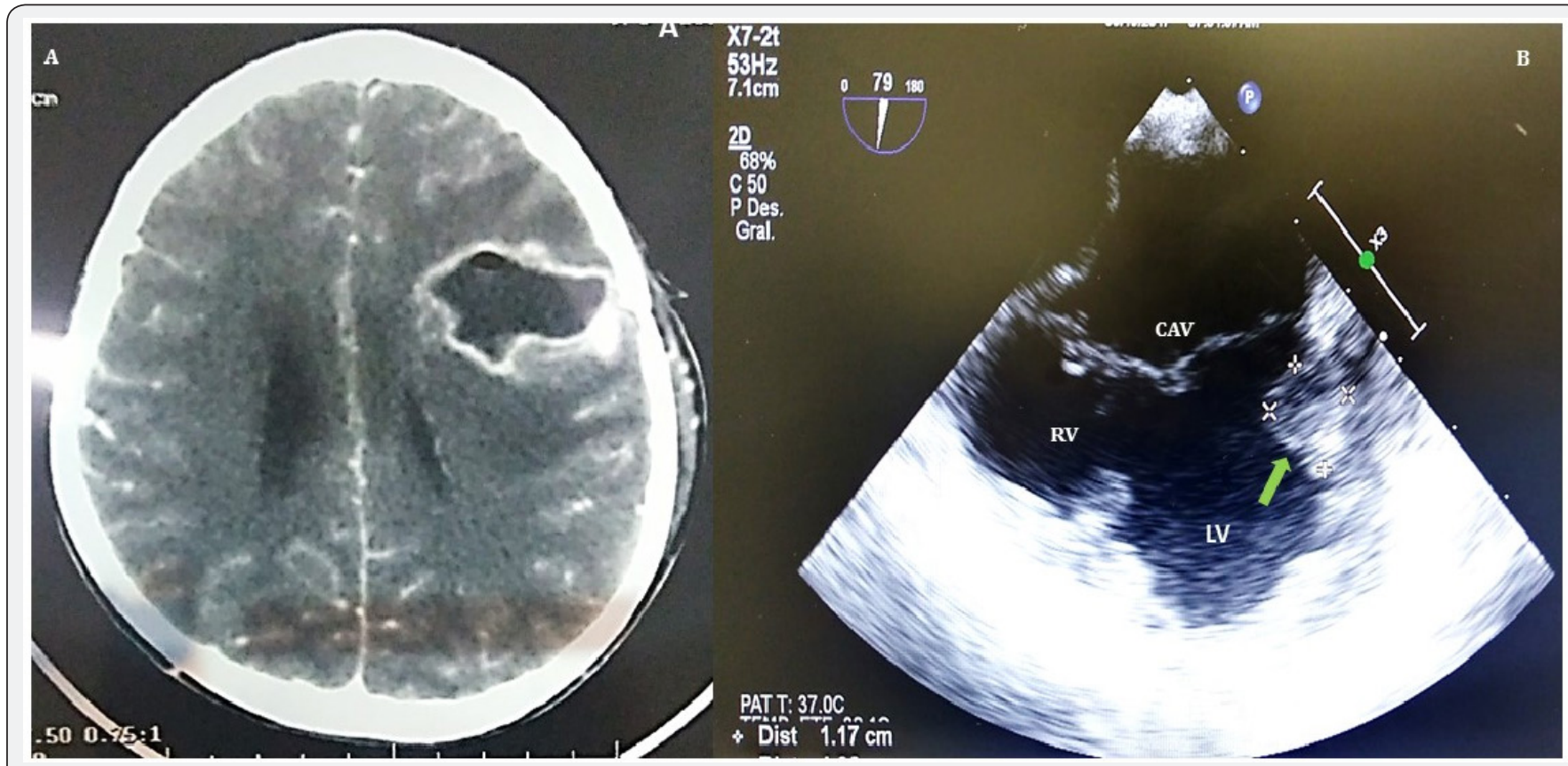

Figure 4:

A: Brain cardioembolic abscess

$\mathrm{B}$ : Transesophageal 4 chamber view in male with $\mathrm{CCHD}$ (unbalanced complet atrioventricular septal defect and single ventricle physiology. CAV: Common Atrioventricular Valve; LV: Left Ventricle; RV: Right Hypoplastic Ventricle; green arrow shows vegetation in subvalvular CAV apparatus.

\section{Gastrointestinal System}

\section{Gall stones}

$\mathrm{SE}$ and the catabolism required to replace old erythrocytes liberate the "heme" group from hemoglobin. As a result, in order to excrete it as a non-toxic substance, the levels of direct or conjugated bilirubin rise, which must then be eliminated through the bile duct. This chronic accumulation is the cause of bile stone formation. They may cause episodes of surgical acute abdomen, with cholecystitis attacks. They are a frequent cause of noncardiac emergency surgery.

\section{Urinary System}

\section{Hyperuricemia}

Secondary hyperuricemia is directly related to the presence of heart failure, a decrease in the excretion of uric acid, and an increase in its reabsorption, rather than to increased production (primary hyperuricemia). Unlike what occurs in the primary form, secondary hyperuricemia does not affect kidney function, or affects it very little. The use of uricosuric drugs in asymptomatic cases is not warranted. A daily dose of colchicine or allopurinol is indicated for cases which produce true gouty arthritis. Acute attacks may be related to the administration of diuretics which decrease the excretion of urates. Hyperuricemia in Eisenmenger syndrome cases is correlated as an independent long-term mortality factor [23].

\section{Kidney failure}

The deterioration of kidney function manifests with proteinuria, decreased glomerular filtration and hyperuricemia. Hyperviscosity increases resistance in the efferent glomerular arteriole, hydrostatic pressure throughout the glomerulus, and the filtration fraction, which causes an increased oncotic pressure in the post-glomerular proximal tubule perfusion vessels, and promotes the reabsorption of liquids and solutes (Figure 5). This reduces the glomerular filtrate and leads to a progressive increase in creatinine levels. There is an increased local production of nitric oxide which causes vasodilation of the afferent and efferent glomerular arterioles, and this is what causes the proteinuria. Albuminuria is the first sign, which may be accompanied by microscopic hematuria. Its incidence increases markedly beginning in the second decade of life, and appears to be related to the duration of cyanosis and the hematocrit levels, being a poor prognostic marker [24-26]. Circulating megakaryocytes are deposited in the mesangial matrix. Finally, there is ischemia and glomerular sclerosis develops, with kidney failure. 


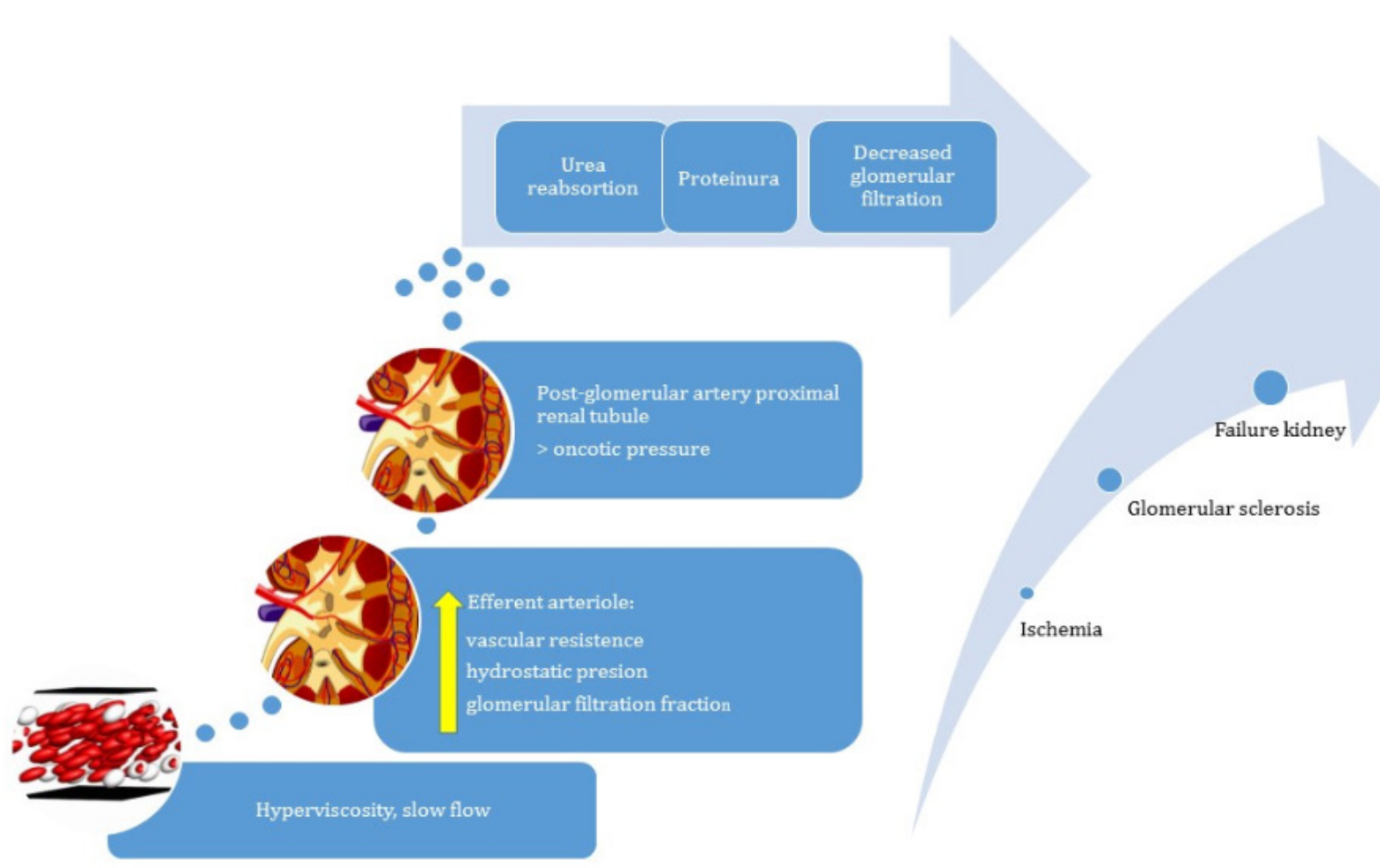

Figure 5:Pathophysiology renal changes in Eisenmenger syndrome

Medications such as angiotensin converting enzyme inhibitors (ACEI), diuretics, nonsteroidal antiinflammatory agents, and some antibiotics should be administered with caution. Their uncontrolled administration may trigger a kidney failure episode.

\section{Cardiovascular System}

Functional cardiac alterations are inherent to the progression of the underlying heart disease, with functional valve alterations secondary to unrepaired structural defects (atrioventricular septal defect and common atrioventricular valve regurgitation, unrepaired atrial septal defect and tricuspid valve regurgitation). Dilation of the heart chambers leads to ventricular functional alterations which deteriorate the ventricular ejection fraction; in consequence, various degrees of congestive heart failure appear. Arrhythmias are a consequence of heart chamber dilation and fibrosis in the context of a CHD. We will not specify this type of lesions in this review.

\section{Altered coronary circulation}

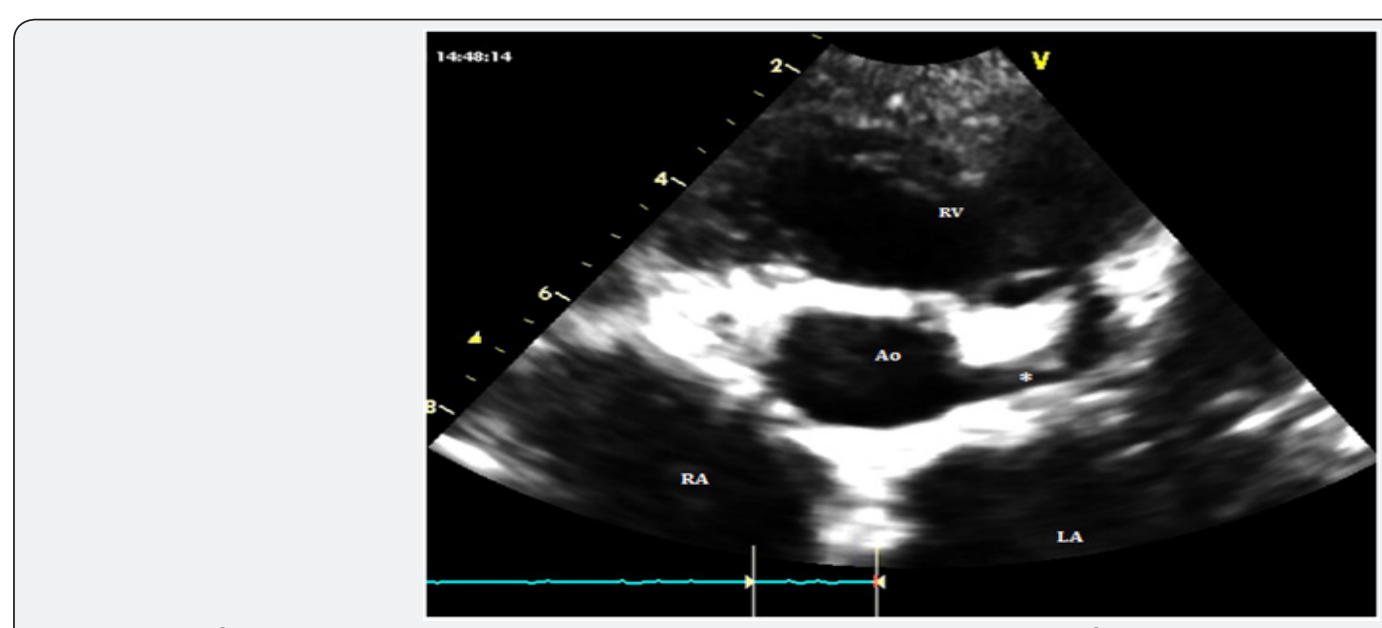

Figure 6: Left common coronary artery trunk is dilated, ectatic and tortuous $\left({ }^{*}\right)$, in female 20 year old with Eisenmenger syndrome and unrepaired large persistent ductus arteriosus. Saturation $70 \%$ on room air. RV: Right Ventricle; RA: Right Atrium; LA: Left Atriu; Ao: Aortic Valve

Endothelial dysfunction manifested as a decreased maximal production of nitric oxide which cannot be increased vasodilation response [27]. Chronic hyperviscosity causes a by other external stimuli, leading to a depleted endothelial cell 
production of nitric oxide (NO). Cyanotic patients have an increased terminal arteriole size and increased density of the small-calibre vessels, and the proximal coronary arteries are dilated, ectatic and tortuous (Figure 6). The histological changes show rupture of the internal elastic lamina, increased collagen in the medial layer, fibrointimal hyperplasia, and an increased extracellular matrix. However, there is no increased risk of atherosclerosis compared with the general population: low cholesterol levels are described as a possible protective factor [28-30]. Ictus events are related more to the presence of septal defects or prosthetic materials than to the coronary artery and microcirculation changes themselves [31].

\section{Systemic hypertension}

Many times its diagnosis goes unnoticed. With the presence of large ventricular septal defects, systemic hypertension is transmitted to the pulmonary circuit, increasing the risk of hemoptysis and rupture of the dilated pulmonary arteries. Systemic antihypertensive treatment is indicated, and should be administered with caution.

\section{Sudden death and arrhythmias}

In the Eisenmenger subgroup, mortality increases 12.8 times compared to the general population [32]. Sudden death has been reported at about $9 \%$. Mortality predictors are: poor functional class (NYHA III or IV), early age at the beginning of symptoms, signs of heart failure, sustained arrhythmia, low albumin and potassium levels, NT-proBNP $\geq 500 \mathrm{ng} / \mathrm{l}$, hyperuricemia, complex $\mathrm{CHD}$, and $\mathrm{SO}_{2}<85 \%$. Echocardiographic predictors include: right atrial area $>25 \mathrm{~cm}^{2}, \mathrm{RA} /$ LA area ratio $>1.5$, peak S wave velocity $<10 \mathrm{~cm} / \mathrm{sec}$, TAPSE $<15 \mathrm{~mm}$. Serial echocardiographic and Holter monitor studies are recommended [33-35].

\section{Immune System}

\section{Infectious complications}

Patients with chronic hypoxemia are susceptible to viral and bacterial respiratory infections which cause serious hemodynamic decompensation. The bacterial germs, in order of frequency, are: pneumococcus, staphylococcus, haemophilus, candida, and pseudomonas [36]. There is an increase in hard-to-treat acne, and the risk of endocarditis caused by Propionibacterium acnes rises in the presence of intracardiac devices [37]. Bacterial endocarditis is serious (many patients cannot be surgically treated due to the severity of CHD). Yearly vaccination against influenza, and every five years against pneumococcus, is recommended. Periodic dental visits and assessment are advised, along with not getting tattoos or piercings. Fingernails should be trimmed frequently and onychophagia avoided, and soft-bristle tooth brushes are recommended to avoid gum trauma and bacteremias [38,39]. Brain abscess is a serious complication; many times intrathecal antibiotic administration is necessary, since the abscesses are heavily encapsulated and poorly permeable to antibiotic treatment.
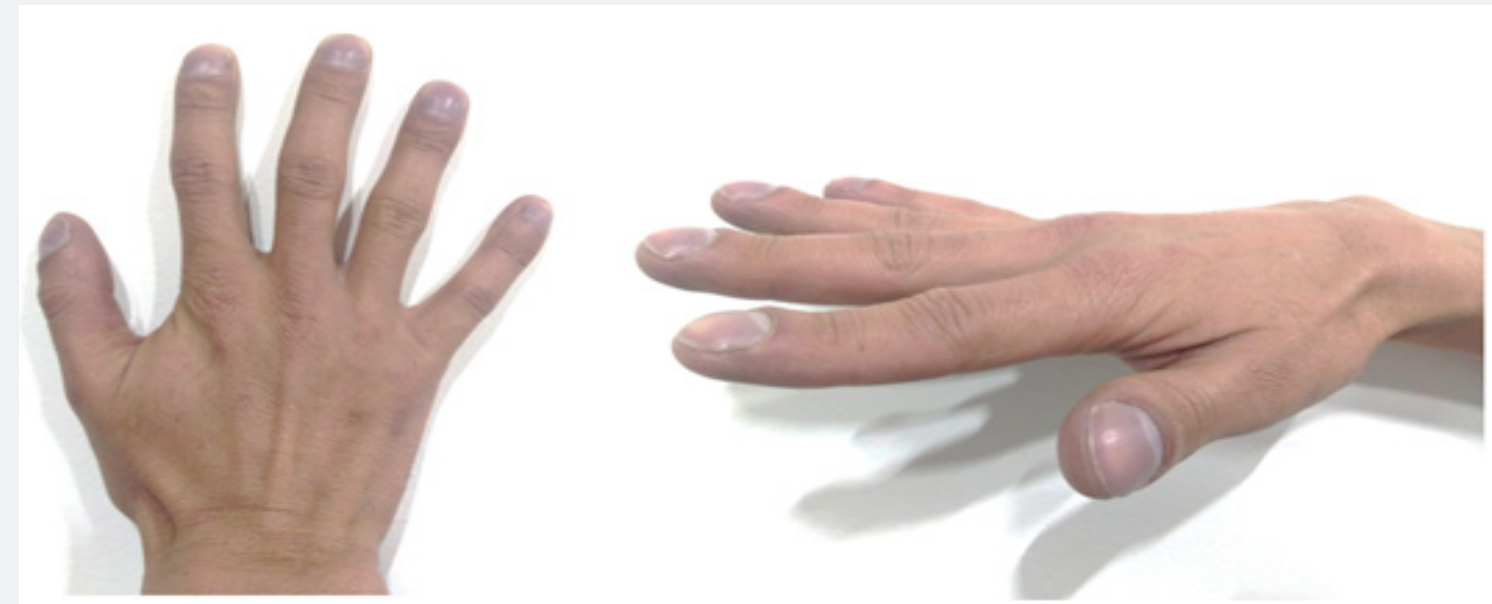

Figure 7: Hypertrophic osteoarthropathy in male 26 year old, Eisenmenger syndrome and unrepaired ventricular septal defect, Saturation $70 \%$ on room air.

\section{Musculoskeletal System}

\section{Hypertrophic osteoarthropathy}

Arthralgias in knees and ankles are frequent; it occurs due to new cellular proliferation and hypertrophic bone formation. Periostitis is especially present in the metacarpals, metatarsals and long bones of the forearm and legs. Nail clubbing, or drumstick fingers, is caused by periosteal thickening, with formation of new bone tissue throughout the diaphysis and metaphysis of the long bones (Figure 7). Its etiology is unknown, but is presumed to be related to hematopoietic factor stimulation in the bone marrow, or bone growth factors which should normally be cleared in the lungs and, due to intracardiac shunts, bypass this step [40]. Another complication which may be seen in adolescents and adults is kyphoscoliosis, which may compromise pulmonary function and aggravate the symptoms.

\section{Exercise intolerance}

There is decreased exercise tolerance compared to the healthy population, even in those with simple defects and who are subjectively asymptomatic. During exercise, there is peripheral vasodilation, with decreased systemic resistance, leading to 
an increased venous-arterial shunt (right to left) through the anatomical heart defects, with increased arterial hypoxemia, hypocapnia and acidosis. Rapid muscle fatigue and tiredness are the consequences. In addition, there is an altered ventilatory dynamic with elevation of the ventilation equivalent (ventilation volume per unit of $\mathrm{CO}_{2}$ produced by exercise; VE/VCO2). A stress test with oxygen may be helpful in evaluating the degree of desaturation triggered by exercise [41-43].

\section{Endocrine System}

\section{Neuroendocrine tumors}

Neuroendocrine neoplasms are described in ACHD and chronic hypoxemia. The origin lies in the mitotic cellular alteration and differentiation of cells in very metabolically active tissues (glands). Pheocromocytomas, paragangliomas, ganglioneuromas and neuroblastomas have been described $[44,45]$, with increased symptomatology, fluid imbalance and general cardiovascular hemodynamics alterations. Alexander et al. described 18 cases of pheocromocytomas and paragangliomas, in a multicenter study. Most of the patients had cardiovascular or psychiatric symptoms. The average length of cyanosis was 20 years (range 1-57). The mean age at diagnosis was 31.5 (15-57 years) and seven cases were multiple tumors. Hospitalized patients with CCHD had a higher probability of tumors (adjusted odds ratio 6.0, 95\% confidence interval 2.6-13.7, $\mathrm{P}<.0001$ ) than those without CHD; patients with non-cyanotic CHD did not have a greater risk (odds ratio $0.9, \mathrm{p}=0.48$ ) [46].

\section{Special Considerations}

\section{Non-cardiac surgeries}

Hemodynamic anesthetic changes such as decreased systemic vascular resistance, increased pulmonary pressure and myocardial depression increase the right to left shunt, leading to more hypoxemia. The loss of volume due to bleeding drastically alters the hemodynamic status with serious decompensation and increased mortality, especially in patients with Eisenmenger syndrome. If these surgeries are strictly necessary and urgent, they should be performed in specialized centers with a multidisciplinary team and a cardiologist specialized in ACHD. Epidural anesthesia causes sympathetic block, affecting preload and post-load. This causes a serious alteration in the hemodynamic state and the risk of death. General anesthesia can be better controlled. Venous lines with air filters should always be used (Figure 2). Bacterial endocarditis prophylaxis should be provided and HS recommendations followed. Arrhythmias and thromboembolic events are frequent, so preventive measures should be taken [47-50].

\section{Prolonged air and ground travel}

The pressurized air in airplanes simulates an altitude of about 1,800-2,400 meters above sea level. Most patients tolerate it well. The gradual ascent of the airplane produces Hgb dissociation curve similar to that of the healthy population. Supplemental oxygen is not necessary during the flight. Airplane cabins are warmer and have less humidity, which favors the loss of fluids and dehydration. Drinking sufficient liquid is recommended, along with not drinking alcoholic beverages or ingesting sedative or anxiolytic medications on long trips (they trigger serious hemodynamic instability and the risk of sudden death). If the destination is at a higher altitude (to that at which the patient usually lives), portable oxygen is recommended when the patient disembarks, as well as having a means of transportation available, in the event of decompensation. Peripheral edemas or headaches have rarely been reported during flights [51].

Prophylactic measures are recommended to avoid deep vein thrombosis (walking, moving legs, choosing aisle seats). Also, the trip should be prepared well in advance and emotional stress avoided. For long trips, additional necessary recommendations should be coordinated with the cabin crew and the ACHD cardiologist.

Long road trips require the same recommendations. If the destination is over 1, 500 meters above sea level, the ascent should be gradual, avoiding rapid climbs which can cause decompensation (visits to mountain or natural park overlooks). These climbs should be carried out with caution and portable oxygen is recommended. Heights over 2,500 meters above sea level are not recommended. Anti-emetics should be administered with caution; they can cause sedation, hypotension, collapse and hemodynamic decompensation [52].

\section{Sports and physical activity}

Avoid isometric exercises (muscle building) or intense effort or competitive activities. Poor oxygenation and muscle metabolism cause rapid fatigue and loss of muscle strength (increased accidents), as well as a high risk of sudden death caused by arrhythmias or a fall in systemic output. Swimming in deep water should be avoided (drowning and gas embolism accidents). All contact sports are contraindicated (risk of major bleeding due to trauma). Long, hot showers or saunas should be taken with caution. Mechanical rides and high jumps are contraindicated [53].

\section{Contraception and pregnancy}

Pregnancy is contraindicated (mortality $>50 \%$ in Eisenmenger cases). Complications occur especially in the third trimester and the first post-partum days. Only $15-25 \%$ of pregnancies get to term, and $50 \%$ have intrauterine growth restriction and prematurity [53]. Increased levels of progestins decrease the systemic vascular resistance, increasing the right to left shunt, which causes severe cyanosis. Vasovagal stimuli or minor bleeds are a cause of sudden death in the Eisenmenger subgroup [53]. Barrier contraception is not effective; potentiation with the use of spermicides is recommended. In the event of a failure, emergency contraception is recommended. Combined oral contraceptives (OCs) are contraindicated (increased thromboembolic risk). Pure progestin OCs is recommended. Subdermal implants are four 
times more effective than surgical sterilization, but they only last for three years, and the local anesthesia used for implantation is well tolerated [54].

Progesterone intrauterine devices are effective and safe, longterm; the only risks during implantation are a vasovagal reaction, minor risk of infection, and scant irregular bleeding during the first months after implantation [55]. Surgical tubal ligation guided by laparoscopy, or the implantation of intratube coils guided by hysteroscopy, is effective. They imply an anesthetic risk, and should only be performed at specialized centers [56].

\section{Conclusion}

Chronic hypoxemic syndrome is a multisystemic disorder. The clinician must not only know the pathophysiology and hemodynamic behavior of the CHD itself, but must also understand the pathophysiological changes that occur in all the organs and systems, paying attention to the early diagnosis of frequent complications. The natural evolution of an adult with CHS oscillates between asymptomatic periods and others with clinical deterioration and the potential risk of death. Management should be undertaken by a multidisciplinary team headed by a cardiologist expert in the care and management of ACHD. Management errors lead to increased morbidity and mortality; therefore, timely follow-up in specialized centers is pertinent.

\section{Acknowledgement}

To my wife and my daughters D.Lynn and Blanquita. Thanks for your support.

\section{References}

1. Marelli A, Ionescu IR, Mackie A, Guo L, Dendukuri N, et al. (2014) Lifetime prevalence of congenital heart disease in the general population from 2000 to 2010. Circulation 130(9): 749-756.

2. Baltaxe E, Zarante I (2006) Prevalencia de malformaciones cardíacas congénitas en 44,985 nacimientos en Colombia. Arch Cardiol Mex 76(3): 263-268.

3. Gatzoulis M, Swan L, Therrien J, Pantely G (2005) Epidemiology of congenital heart disease. In: Gatzoulis M, Swan L, Therrien J, Pantely G (Eds.), Adult congenital heart disease: A practical guide, $\left(1^{\text {st }}\right.$ edn), BMJ Books, London, UK, pp. 3-7.

4. Douglas M (2011) Adult congenital heart disease: Past, present, and future. Tex Heart Inst J 38(6): 705-706.

5. Baumgartner H (2014) Geriatric congenital heart disease: a new challenge in the care of adults with congenital heart disease? Eur Heart J 35(11): 683-685.

6. Nguyen L, Maul T, Hindes M, Daniels C, Gurvitz M, et al. (2015) Current and future status of adult congenital training in North America. Am J Cardiol 115(8): 1151-1153.

7. Gilboa S, Devine O, Kucik J, Oster M, Riehle CT, et al. (2016) Congenital heart defects in the United States estimating the magnitude of the affected population in 2010. Circulation 134(2): 101-109.

8. Ruiz J (2003) Cardiopatías congénitas del adulto: residuos, secuelas y complicaciones de las cardiopatías congénitas operadas en la infancia. Rev Esp Cardiol 56(1): 73-88.

9. Perloff JK (2008) Cyanotic congenital heart disease: a multisystem disorder. In: Perloff JK, Child JS, Aboulhosn J (Eds.), Congenital Heart Disease in Adults, ( $3^{\text {rd }}$ edn), Elsevier, Philadelphia, USA, pp. 265-289.
10. Broberg C, Bax B, Okonko D, Rampling M, Bayne S, et al. (2006) Blood viscosity and its relationship to iron deficiency, symptoms, and exercise capacity in adults with cyanotic congenital heart disease. J Am Coll Cardiol 48(2): 356-365.

11. Diller G, Dimopoulos K, Broberg C, Kaya M, Naghotra U, et al. (2006) Presentation, survival prospects, and predictors of death in Eisenmenger syndrome: a combined retrospective and case-control study. Eur Heart J 27(14): 1737-1742.

12. Perloff J, Rosove M, Child J, Wright G (1998) Adults with cyanotic congenital heart disease: hematologic management. Ann Intern Med 109(5): 406-413.

13. Oechslin E (2011) Eisenmenger syndrome. In: Gatzoulis M, Webb G, Daubeney P (Eds.), Diagnosis and Management of Adult Congenital Heart Disease, (2 ${ }^{\text {nd }}$ edn), Elsevier Saunders, London, UK, pp. 358-370.

14. Broberg C, Ujita M, Babu NS, Rubens M, Prasad S, et al. (2004) Massive pulmonary artery thrombosis with haemoptysis in adults with Eisenmenger's syndrome: a clinical dilemma. Heart 90(11): e63.

15. Broberg C, Ujita M, Prasad S, Li W, Rubens M, et al. (2007) Pulmonary arterial thrombosis in Eisenmenger syndrome is associated with biventricular dysfunction and decreased pulmonary flow velocity. J Am Coll Cardiol 50(7): 634-642.

16. Sandoval J, Santos L, Córdova J, Pulido T, Gutiérrez G, et al. (2012) Does anticoagulation in Eisenmenger syndrome impact long-term survival? Congenit Heart Dis 7(3): 268-276.

17. Sakazaki H, Niwa K, Echigo S, Akagi T, Nakazawa M (2007) Predictive factors for long-term prognosis in adults with cyanotic congenital heart disease-Japanese multi-center study. Int J Cardiol 120(1): 72-78.

18. Lill M, Perloff J, Child J (2006) Pathogenesis of thrombocytopenia in cyanotic congenital heart disease. Am J Cardiol 98(2): 254-258.

19. Warnes C, Williams R, Bashore T, Child J, Connolly H, et al. (2008) ACC/ AHA 2008 guidelines for the management of adults with congenital heart disease. J Am Coll Cardiol 52(23): 143-263.

20. Wan D, Tsui C, Kiess M, Grewal J, Krahn A, et al. (2017) Anticoagulation for thromboembolic risk reduction in adults with congenital heart disease. Can J Cardiol 33(12): 1597-1603.

21. Wan D, Tsui C, Grewal J, Kiess M, Barlow A, et al. (2017) Thromboembolic episodes related to atrial arrhythmias in adults with transposition of great arteries. J Cong Cardiol 1: 6 .

22. Oya H, Nagaya N, Satoh T, Sakamaki F, Kyotani S, et al. (2000) Haemodynamic correlates and prognostic significance of serum uric acid in adult patients with Eisenmenger syndrome. Heart 84(1): 53-58.

23. Kempny A, Diller G, Alonso GR, Uebing A, Rafiq I, et al. (2015) Hypoalbuminaemia predicts outcome in adult patients with congenital heart disease. Heart 101(9): 699-705.

24. Dimopoulos K, Diller G, Koltsida E, Pijuan DA, Papadopoulou S, et al. (2008) Prevalence, predictors, and prognostic value of renal dysfunction in adults with congenital heart disease. Circulation 117(18): 2320-2328.

25. Grewal J, Brunner N, Ellis J, Swiston J, Leipsic J, et al. (2016) Special considerations in the management of adult congenital heart disease. BCMJ 58(7): 381-388.

26. Oechslin E, Kiowski W, Schindler R, Bernheim A, Julius B, et al. (2005) Systemic endothelial dysfunction in adults with cyanotic congenital heart disease. Circulation 112: 1106-1112.

27. Tarp J, Jensen A, Engstrøm T, Holstein RN, Søndergaard L (2017) Cyanotic congenital heart disease and atherosclerosis. Heart 103(12): 897-900.

28. Duffels M, Mulder K, Trip M, de Groot E, Gort J, et al. (2010) Atherosclerosis in patients with cyanotic congenital heart disease. Circulation 74(7): 1436-1441. 
29. Chugh R, Perloff J, Fishbein M, Child J (2004) Extramural coronary arteries in adults with cyanotic congenital heart disease. Am J Cardiol 94(10): 1355-1357.

30. Bokma J, Zegstroo I, Kuijpers J, Konings T, van Kimmenade R, etal. (2017) Factors associated with coronary artery disease and stroke in adults with congenital heart disease. doi: 10.1136/heartjnl-2017-311620.

31. Dimopoulos K, Inuzuka R, Goletto S, Giannakoulas G, Swan L, et al. (2010) Improved survival among patients with eisenmenger syndrome receiving advanced therapy for pulmonary arterial hypertension. Circulation 121(1): 20-25.

32. Alonso GR, Lopez GC, Subirana DM, Ruíz J, González I, et al. (2015) Pulmonary hypertension and congenital heart disease: An insight from the REHAP national registry. Int J Cardiol 184: 717-723

33. Gerhard PD, Konstantinos D, Craig S, Mehmet G, Utpal S, et al (2006) Presentation, survival prospects, and predictors of death in Eisenmenger syndrome: a combined retrospective and case-control study. European Heart J 27(14): 1737-1742.

34. Schuuring M, van Riel A, Vis J, Duffels M, van Dijk A, et al. (2015) New predictors of mortality in adults with congenital heart disease and pulmonary hypertension: Midterm outcome of a prospective study. Int J Cardiol 181: 270-276

35. Ishiwada N, Niwa K, Tateno S, Yoshinaga M, Terai M, et al. (2005) Causative organism influences clinical profile and outcome of infective endocarditis in pediatric patients and adults with congenital heart disease. Circ J 69(10): 1266-1270.

36. Santo K, Franceschi V, Campos A, Monteiro T, Barbosa G, et al. (2014) Pacemaker endocarditis caused by Propionibacterium acnes in an adult patient with Ebstein's anomaly: a report of a rare case. Heart Lung Circ 23(10): 222-225.

37. Habib G, Lancellotti P, Antunes M, Bongiorni M, Casalta J, et al. (2016) 2015 ESC Guidelines for the management of infective endocarditis. The task force for the management of infective endocarditis of the European Society of Cardiology (ESC). G Ital Cardiol (Rome) 17(4) 277-319.

38. Schmidt S, Ramseier HM, Thomet C, Wustmann K, Schwerzmann M (2017) Gender-related differences in self reported dental care in adults with congenital heart disease at increased risk of infective endocarditis Open Heart 4(1): e000575. doi:10.1136/openhrt-2016-000575.

39. Wijesekera V, Radford D (2013) Hypertrophic osteoarthropathy in Eisenmenger syndrome. Congenit Heart Dis 8(3): 65-69.

40. Diller G, Dimopoulos K, Okonko D, Li W, Babu NS, et al. (2005) Exercise intolerance in adult congenital heart disease: comparative severity, correlates, and prognostic implication. Circulation 112(6): 828-835.

41. Mantegazza V, Apostolo A, Hager A (2017) Cardiopulmonary exercise testing in adult congenital heart disease. Ann Am Thorac Soc 14(Suppl 1): S93-S101.

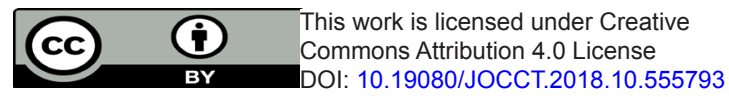

42. Wang J, Liu B (2017) Exercise and congenital heart disease. Adv Exp Med Biol 1000: 95-101

43. Kita T, Imamura T, Date H, Kitamura K, Moriguchi S, et al. (2003) Two cases of pheochromocytoma associated with tetralogy of Fallot. Hypertens Res 26(5): 433-437.

44. Ponz de AI, Ruiz CJ, González GA, Oliver RJ, Sánchez RÁ, et al. (2017) Prevalence of neuroendocrine tumors in patients with cyanotic congenital heart disease. Rev Esp Cardiol (Engl Ed) 70(8): 673-675.

45. Opotowsky A, Moko L, Ginns J, Rosenbaum M, Greutmann M, et al. (2015) Pheochromocytoma and paraganglioma in cyanotic congenital heart disease. J Clin Endocrinol Metab 100(4): 1325-1334.

46. Junghare S, Desurkar V (2017) Congenital heart diseases and anaesthesia. Indian J Anaesth 61: 744-752.

47. Egbe A, Khan A, Ammash N, Barbara D, Oliver W, et al. (2017) Predictors of procedural complications in adult Fontan patients undergoing noncardiac procedures. Heart 103(22): 1813-1820.

48. Cannesson M, Earing M, Collange V, Kersten J (2009) Anesthesia for noncardiac surgery in adults with congenital heart disease. Anesthesiology 111: 432-440.

49. Yamamoto T, Schindler E (2016) Anaesthesia management for non-cardiac surgery in children with congenital heart disease. Anaesthesiology Intensive Therapy 48(5): 305-313.

50. Broberg C, Uebing A, Cuomo L, Thein S, Papadopoulos M, et al. (2007) Adult patients with Eisenmenger syndrome report flying safely on commercial airlines. Heart 93(12): 1599-1603.

51. Marzi M, Weitz D, Avila A, Molina G, Caraballo L, et al. (2015) Cardiac adverse effects of domperidone in adult patients: a systematic review. Rev Med Chile 143(1): 14-21.

52. Pijuan DA, Gatzoulis M (2006) Embarazo y cardiopatía. Rev Esp Cardiol 59(9): 971-984

53. Connolly H, Warnes C (2011) Pregnancy and contraception. In: Gatzoulis M, Webb G, Daubeney P (Eds.), Diagnosis and Management of Adult Congenital Heart Disease, (2 ${ }^{\text {nd }}$ edn), Elsevier Saunders, London, UK, pp. 158-164.

54. Pijuan DA, Baró MF, Rojas TM, Subirà L, Pedrosa DMV, et al. (2013) Usefulness of progesterone-only components for contraception in patients with congenital heart disease. Am J Cardiol 112(4): 590-593.

55. Winner B, Peipert J, Zhao Q, Buckel C, Madden T, et al. (2012) Effectiveness of long-acting reversible contraception. N Engl J Med 366: 1998-2007.

56. Regitz ZV, Blomstrom C, Borghi C, Cifkova R, Ferreira R, et al. (2011) ESC guidelines on the management of cardiovascular diseases during pregnancy: the task force on the management of cardiovascular diseases during pregnancy of the European Society of cardiology (ESC). Eur Heart J 32(24): 3147-3197.

\section{Your next submission with Juniper Publishers will reach you the below assets}

- Quality Editorial service

- Swift Peer Review

- Reprints availability

- E-prints Service

- Manuscript Podcast for convenient understanding

- Global attainment for your research

- Manuscript accessibility in different formats

( Pdf, E-pub, Full Text, Audio)

- Unceasing customer service

Track the below URL for one-step submission https://juniperpublishers.com/online-submission.php 